\title{
The Rhode Island Nuclear Science Center Conversion from HEU to LEU Fuel
}

\author{
T. Tehan, Ph.D. \\ Director, Rhode Island Nuclear Sciencesefentqearance Granted \\ Narragansett, Rhode

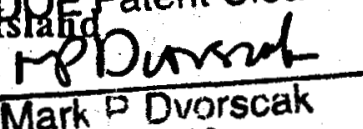 \\ $\frac{10 \cdot 3-01}{\text { Date }}$ \\ ABSTRACT (630) 25?-2393 \\ (630) 25?-2393 \\ E-mail mark.dvorscar \\ Office of intellectual Property Law
}

The $2 \mathrm{MW}$ Rhode Island Nuclear Science Cenler (RINSC) open pool reactor was converted from 93\% UAL-High Enriched Uranium (HEU) fuel to $20 \%$ enrichment $\mathrm{U}_{3} \mathrm{Si}_{2}$ -Al Low Enriched Uranium (LEU) fuel. The conversion included redesign of the core to a more compact size and the addition of beryllium reflectors and a beryllium flux trap. A significant increase in thermal fux level was achieved due to greater neutron leakage in the new compact core configuration. Following the conversion, a second cooling loop and an emergency core cooling system were installed to permit operation at $5 \mathrm{MW}$. After re licensing at $2 \mathrm{MW}$, a power upgrade request will be submitted to the NRC.

\section{INTRODUCTION}

Conversion of the RINSC research reactor began in August, 1986 with the award of a Department of Energy (DOE) grant to convert the fuel system from $93 \%$ enrichment UAL fuel to a nominal $20 \%$ enrichment $\mathrm{U}_{3} \mathrm{Si}_{2}-\mathrm{Al}$ fuel. As part of the conversion, priority was given to designing the core for greater flux at existing power levels. Also, consideration was given to ensuring that the new core would be capable of operating at higher power levels. The facility "in concrete" structures and control systems were designed for operation at $5 \mathrm{MW}$ but necessary support systems were not installed due to funding constraints. As part of the core design process, critical operating parameters for operation at $5 \mathrm{MW}$ were determined.

The conversion program consisted of five phases: design of the new core, completion of a Safety Analysis Report (SAR), shipment of spent HEU fuel, modifications to reactor systems and new core load, and the test program. The shutdown time for conversion to the new fuel system was utilized to install a new $3 \mathrm{MW}$ cooling tower, digital wide range power level instruments and a larger secondary piping system which were provided through DOE Reactor Instrumentation Program grants.

\section{BACKGROUND}

The operating license for the RINSC reactor was issued on July 21,1964 with an expiration date of August 27,2002. The original license permitted operation at a power level of $1 \mathrm{MW}$. An amendment to the license was issued on September 10, 1968 which permitted operation at $2 \mathrm{MW}$. The conversion order to switch from high to low enriched uranium fuel was issued on March 17, 1993 following approval of the revised Safety Analysis Report. The license was amended on July 28, 2000 to extend the expiration date 
to July 21,2004 . A contractor is updating the Safety Analysis Report to support submission of a license renewal for an additional twenty year period.

The reactor system consists of a $7 \times 9$ grid box with the four corner grid positions occupied by suspension frame comer posts. These comer posts connect the grid box to the reactor bridge which spans the open pool. The hollow posts each contain a neutron detector required for operation of the reactor. The grid plate is suspended about 8 meters ( 26.33 feet) below the pool water surface. The grid box also contains two permanently installed shrouds in which four boral control safety blades (rods) move. A stainless steel regulating rod is located in the reflector area and is used for fine control of flux level.

The LEU conversion core consists of a compact configuration using 22 standard plates per fuel element and a combination of graphite and beryllium reflectors. The fuel is a uranium-silicide-aluminum dispersion and each element contains 275 grams of $U$ 235. There are fourteen fuel elements which surround a central beryllium flux trap. Graphite and beryllium reflectors surround the core. The beryllium reflectors start on the outer periphery of the grid box and are moved inward in groups as the reactivity decreases due to fuel burn up. The initial startup configuration is shown in Figure 1.

\section{DESIGN PHASE}

The design phase focused on six basic criteria and objectives of the conversion program. They were:

1. Convert the reactor to LEU using the standard design DOE fuel plate.

2. Design a core with a greater fuel burnout than the present $14 \%$.

3. Design a core which would optimize the thermal flux in the beam tubes and allow for further improvement.

4. Design a core with a flux trap for small sample irradiation.

5. Design a core capable of $5 \mathrm{MW}$ operation with higher primary flow.

6. Design a core with the same cost as a replacement HEU core.

The neutronic core design was performed using the standard LEU fuel plate provided by DOE. This plate is thinner and contains considerably more uranium-235 than the HEU plate (275 grams/plate for LEU and 124 grams/plate for HEU). Because of the heavy fuel loading of the LEU plate, a major concern was that the core might become so small that the control blades might lose their effectiveness. Many core configurations were considered.' These studies included consideration of: 


\section{DISCLAIMER}

This report was prepared as an account of work sponsored by an agency of the United States Government. Neither the United States Governmeat nor any agency thereof, nor any of their employees, makes any warranty, express or implied, or assumes any legal liability or responsibility for the accuracy, completeness, or usefulness of any information, apparatus, product, or process disclosed, or represents that its use would not infringe privately owned rights. Reference herein to any specific commercial product, process, or service by trade name, trademark, manufacturer, or otherwise does not necessarily constitute or imply its endorsement, recommendation, or favoring by the United States Government or any agency thereof. The views and opinions of authors expressed herein do not necessarily state or reflect those of the United States Governmeat or any agency thereof. 


\section{DISCLAIMER}

Portions of this document may be illegible in electronic image products. Images are produced from the best available original document. 
INITIAL CORE LOADING

Percent Power - 14 elements Core \#1

Core Lifetime -14 Wks ( 560 Full Power Hours)

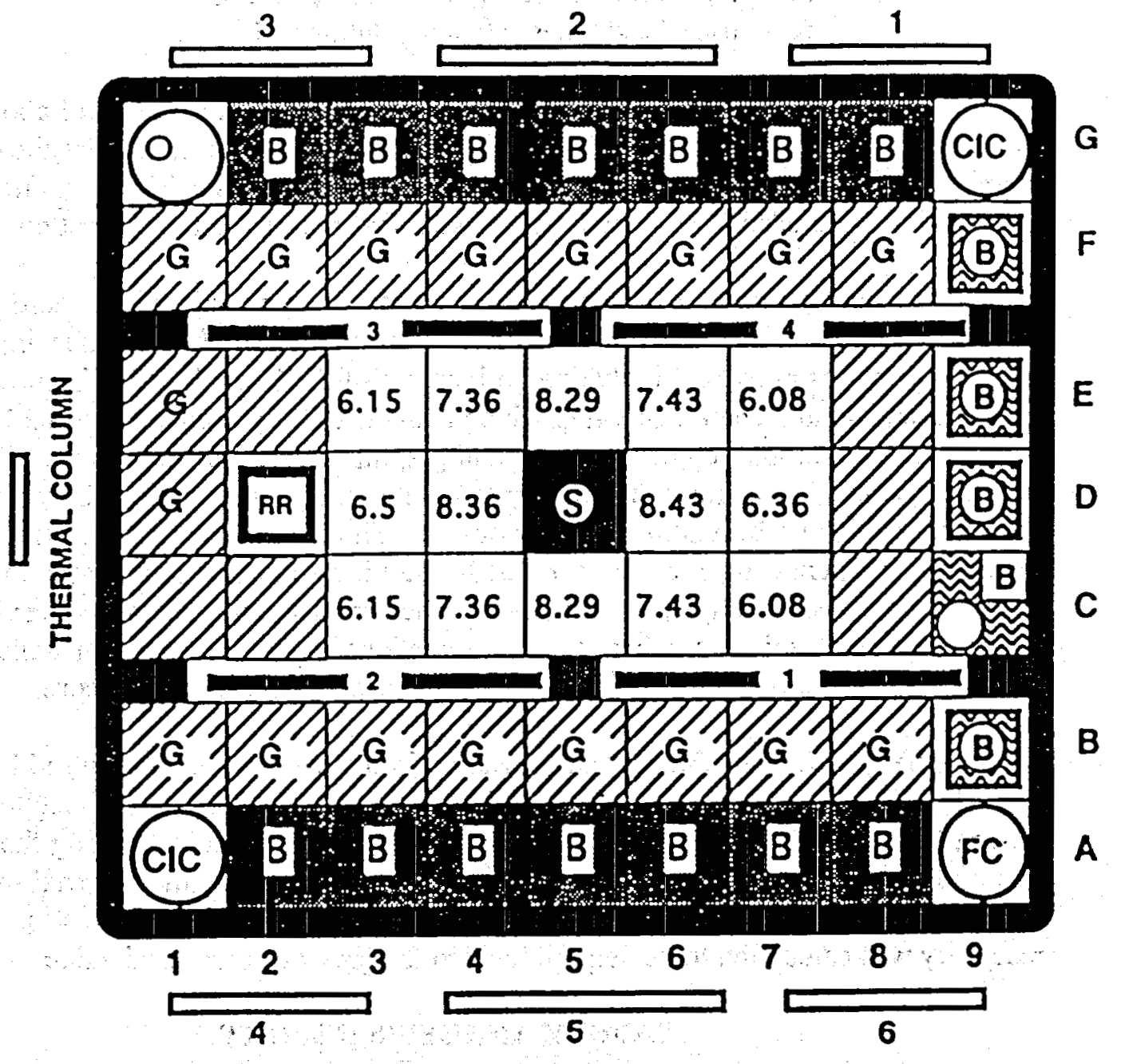

FIGURE 1 
1. 18 fuel plate elements

2. 22 fuel plate elements

3. several fuel element arrangements

4. graphite and beryllium reflectors

5. relocation of the regulating rod position

6. use of a stainless steel regulating rod.

The neutronic calculations were performed by Argonne National Laboratory using the EPRI Cell, DIF 3D, and VIM Monte Carlo Codes. The thermal-hydraulic calculations were done by RINSC using PLTEMP and NACON codes. These results and other information were used to develop a final design that optimized the project objectives.

The conversion core uses fuel elements that each contain 22 standard plates. The - Uranium silicide-aluminum dispersion fuel has significant performance improvements over the previous alloy fuel including an increase of $50 \%$ in allowable burn up. The fuel elements surround a central flux trap which is made of beryllium and has a $38 \mathrm{~mm}$ hole in the center. A combination of beryllium and graphite reflectors was chosen. This allowed a cost savings by using the existing graphite reflectors while achieving improved performance from a beryllium reflector design. The mix of the two materials provides a means of compensating for fuel burnout by moving the beryllium closer to the fuel to achieve increased reactivity in the core. The smaller core geometry results in more neutron leakage which is enhanced by interactions with the beryllium which produces more neutrons and results in a greater flux at the beam ports and in the core.

The geometry of the new core resulted in the existing regulating rod being too far from the flux for adequate control. Moving the rod in closer to the fuel resulted in the rod having too much reactivity worth. This problem was resolved by moving the location in one grid block to increase the reactivity of the rod and changing the material from boral to stainless steel to decrease the reactivity worth of the rod. The net effect on control rod reactivity was calculated to be negligible from the previous measured value.

\section{SAFETY ANALYSIS REPORT}

The neutronic and thermal-hydraulic calculations for the new core compared favorably with the performance of the HEU core. The design basis accident for the reactor was determined to be a loss of coolant accident with the water draining through a beam port and the associated drain. Since the LEU core has a higher power density, there was a possibility of exceeding thermal limits if the fuel was not adequately cooled. The core sits in a grid box which has a drain hole in the bottom that is $1.25 \mathrm{~cm}$ in diameter. By restricting the allowed opening in beam ports that are in use to an effective $1.25 \mathrm{~cm}$ diameter hole, it was found that the LEU core will not suffer melting following a loss of coolant accident.

The original analysis of the effects of a fission product release from a fuel element failure was completely revised to make use of the considerable increase in knowledge in this area since the initial Safety Analysis was completed. A worst case scenario was developed where a fuel plate was damaged and all available fission product gases were 
released. Considerable conservatism was used in calculating power history and the volume of activity released to the building and surrounding area. The calculated exposures were well within regulatory limits.

As part of the Safety Analysis, the Technical Specifications for the facility were required to be modified to reflect the LEU conversion. The existing Technical Specifications were essentially unchanged from the original 1964 version and were not in compliance with current standards. ANSI N378, Standard for the Development of Technical Specifications for Research Reactors, and other references supplied by the NRC were utilized to completely rewrite the Facility Technical Specifications. This exercise was very beneficial for the staff because it focused attention on the operational and casualty concerns associated with the new core and the necessary technical review provided an excellent vehicle for improving staff technical and operational knowledge just prior to the actual conversion work.

\section{SPENT FUEL SHIPMENT}

Prior to receipt of the new core, it was necessary to remove a large inventory of spent fuel so that space would be available for storage of the old HEU core when it was removed. The limiting item in this process was availability of the BMI shipping cask. This container is the only one available for shipping university MTR fuel and is usually in high demand. To maximize the number of elements in each shipment, the end pieces were cut off of each fuel element so that just the fuel region of the assembly was loaded in the cask. This process doubled the number of spaces available in the cask from 12 to 24. A total of 34 elements with 18,767 curies of activity were transported to Savannah River in two shipments during January, 1993. When the HEU core was unloaded to storage racks in the pool, 12 of the 30 fuel elements were within 2 grams of their burn up limit. An additional $39 \mathrm{HEU}$ fuel elements were subsequently shipped which left no spent fuel at the facility.

\section{CORE MODIFICATIONS}

The HEU core was unloaded in the second week of July, 1993 and work began on moving the regulating rod. High radiation levels at the top of the grid box resulted in the decision to keep the water level at the top of the grid box. In this condition, readings of 1 to $2 \mathrm{Rem} / \mathrm{hr}$ were still found at the top of the grid box. The old regulating rod was removed by cutting the control shaft near the top of the support frame and transporting the assembly with a lanyard to the spent pool fuel. The sleeve for the regulating rod was removed by attaching a lanyard to a vice grip pliers and attaching the pliers to the lip of the sleeve. The sleeve was then transported to the spent fuel pool. Both these items were highly radioactive and the procedure was carried out rapidly to minimize exposure.

The new regulating rod sleeve was installed to the grid box by a brace at the top of the assembly which spanned the top of one graphite reflector. The regulating rod was installed with a new control shaft which had a 3 inch bend to accommodate the shift inward one grid position. A bearing was installed on the support frame to ensure proper 
alignment of the regulating rod. The rod was operationally tested before the core load. The total exposure received during this work was $40 \mathrm{mrem}$.

The new fuel arrived from Babcock and Wilcox on August 3, 1993. After receipt inspection, it was stored in fuel storage racks in the pool. The beryllium reflectors arrived on August 16, 1993 and were also inspected and placed in storage racks in the pool. Four extra LEU fuel elements were inspected and stored in the fuel safe.

\section{CORE LOAD}

Due to the small size of the core, it was decided to do $1 / \mathrm{M}$ reactivity calculations after each element was loaded. To ensure that there was no problem with detecting an increase in counts during the criticality experiment, the test source was placed in a basket in the middle of the core where the flux trap would normally be located. This geometry allowed the four detectors that are located in the corner posts to monitor the flux. Fuel elements were tested for fit and then loaded in a symmetric pattern around the flux trap. The count rates with blades in and blades out increased steadily with each fuel element addition and it appeared that criticality would be achieved with 12 elements. When the twelfth element was loaded, the reactor increased counts but would not go critical. After a review of the data and calculations, it was determined that there was too much reactivity loss in the center of the core from the flux trap being replaced by the test source. The blades were inserted. The test source was moved to its normal location and the flux trap was inserted into the center of the core. Criticality was achieved after blades one, two and three had been fully withdrawn and blade 4 was at seventeen inches.

\section{PHYSICS TESTING}

Upon completion of the initial fourteen element core load, a test program was conducted to determine the physics parameters of the new core. The initial set of blade worth curves indicated that the blades had much less worth than estimated and the values were not consistent between the blades. Foils and wires were used to map the flux in the core and all data was sent to Argonne Laboratory for analysis. Laboratory results indicated that the data was consistent with predicted values.

RINSC's procedure for determining blade worth was reviewed and it was found that criticality was achieved by pulling rods to the top and then the next rod was used for rod worth calculations as it was pulled out. This procedure worked well for the old core which was large and surrounded all the blades. The compactness of the new core resulted in the blades being located outside of the fuel with their inner sides facing the fuel elements. As a result, the existing procedure caused a significant flux tilt with three rods out and one in. After reviewing rod calibration procedures from other research reactors, the procedure was revised to bank all rods but the one being tested at the same level and then pull the rod under test through the flux. This procedure resulted in the rod worth values becoming uniform within $10 \%$ but their total worth was still too low.

Initial physics testing was being done at very low power levels in order to minimize personnel exposure while conducting a complete flux map of the core. Each 
critical testing period resulted in a significant increase in the source counts in the core as the beryllium was irradiated. Blade worth calculations were based on the Inhour formula which uses the observed period to compute reactivity. ${ }^{2}$ This calculation does not take source neutrons into consideration. When it became apparent that the low blade worths were due to interference from the source neutrons, flux mapping was completed and then the rod calibrations were conducted at a power level two decades above the power level at which criticality was achieved. The resulting rod calibration data was much closer to predicted values but still slightly low.

The low burn up of the LEU fuel resulted in the control rod position being low in the core. The resulting axial flux pattern as shown in Figures 2 and 3 was correspondingly high at the bottom and much lower at the top of the core. Since the neutron monitoring detectors are located in the corner posts above the core, it appeared that significant shielding of the flux might result from the geometry of the detectors. When two detectors were lowered next to the grid box in the pool, the flux increased by a factor of twenty for a given power level. It was clear that the compact core was more sensitive to detector position than the previous HEU core which routinely ran with the blades near the top of the core. The resulting flux profile was much flatter and provided more flux at the detectors.

To maintain the flux high in the core, the graphite and beryllium elements were adjusted to maintain core reactivity low enough to keep the rods out during normal operation. LEU Core \#1A (Figure 4) shows the first modification from the original core configuration and LEU Core \#2 (Figure 5) shows the next configuration utilized to maintain rod level high in the core. The final configuration will have all the Beryllium reflectors next to the core 
Flux Trap Thermal Flux at $2 M W$

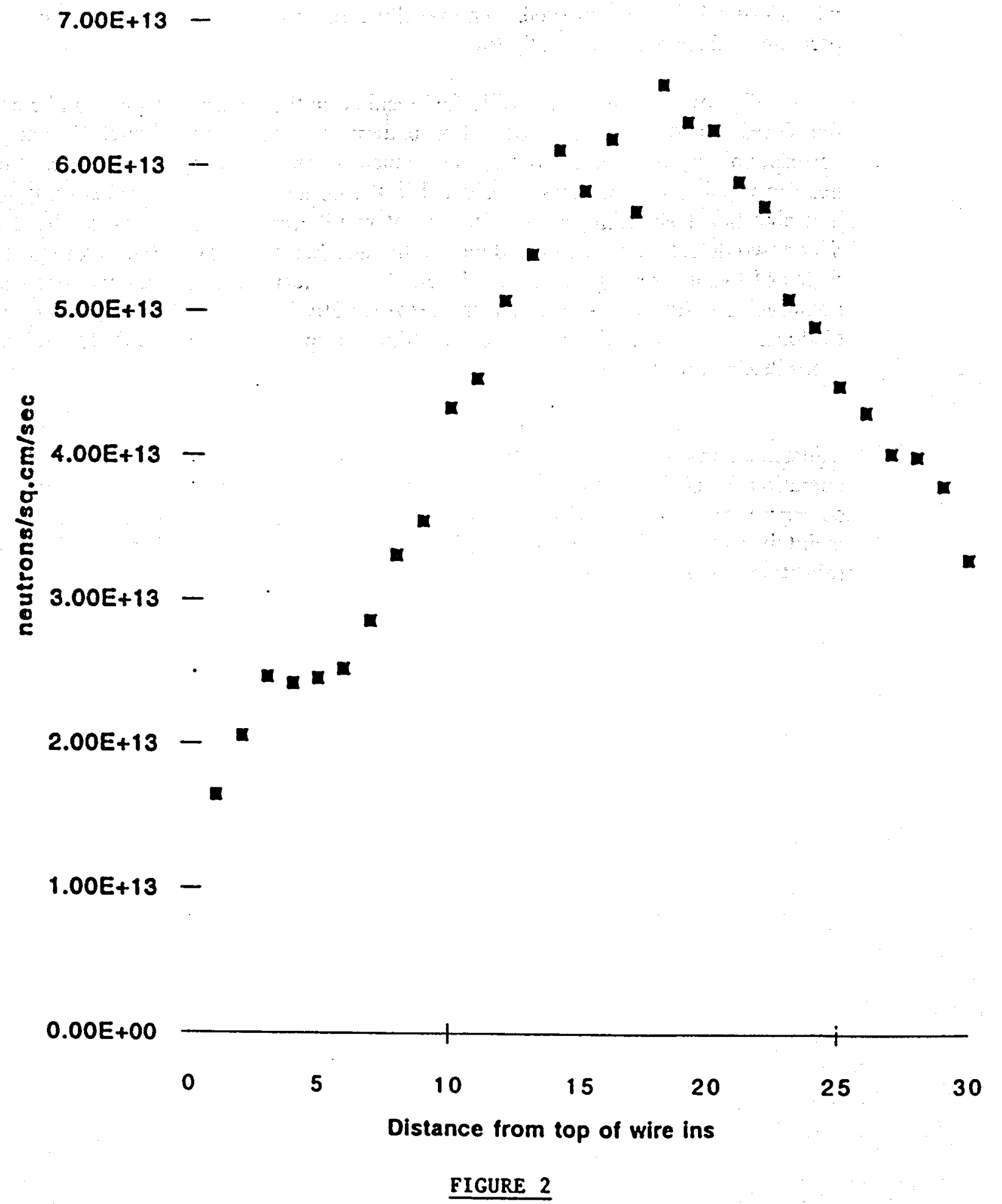


Thermal Flux (2MW) in Irrad Basket (Incore Device)

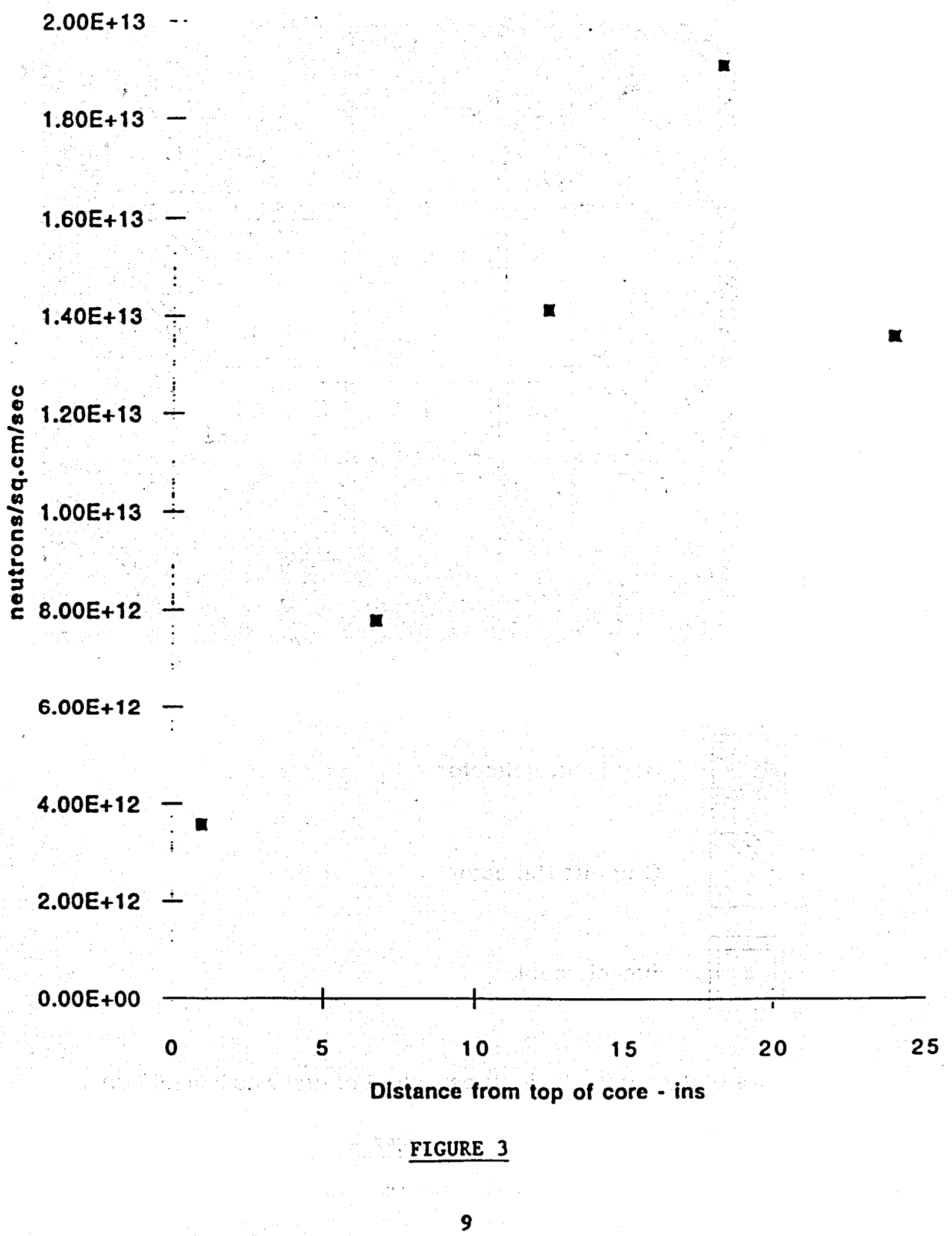




\section{LEU CORE \# 1A}

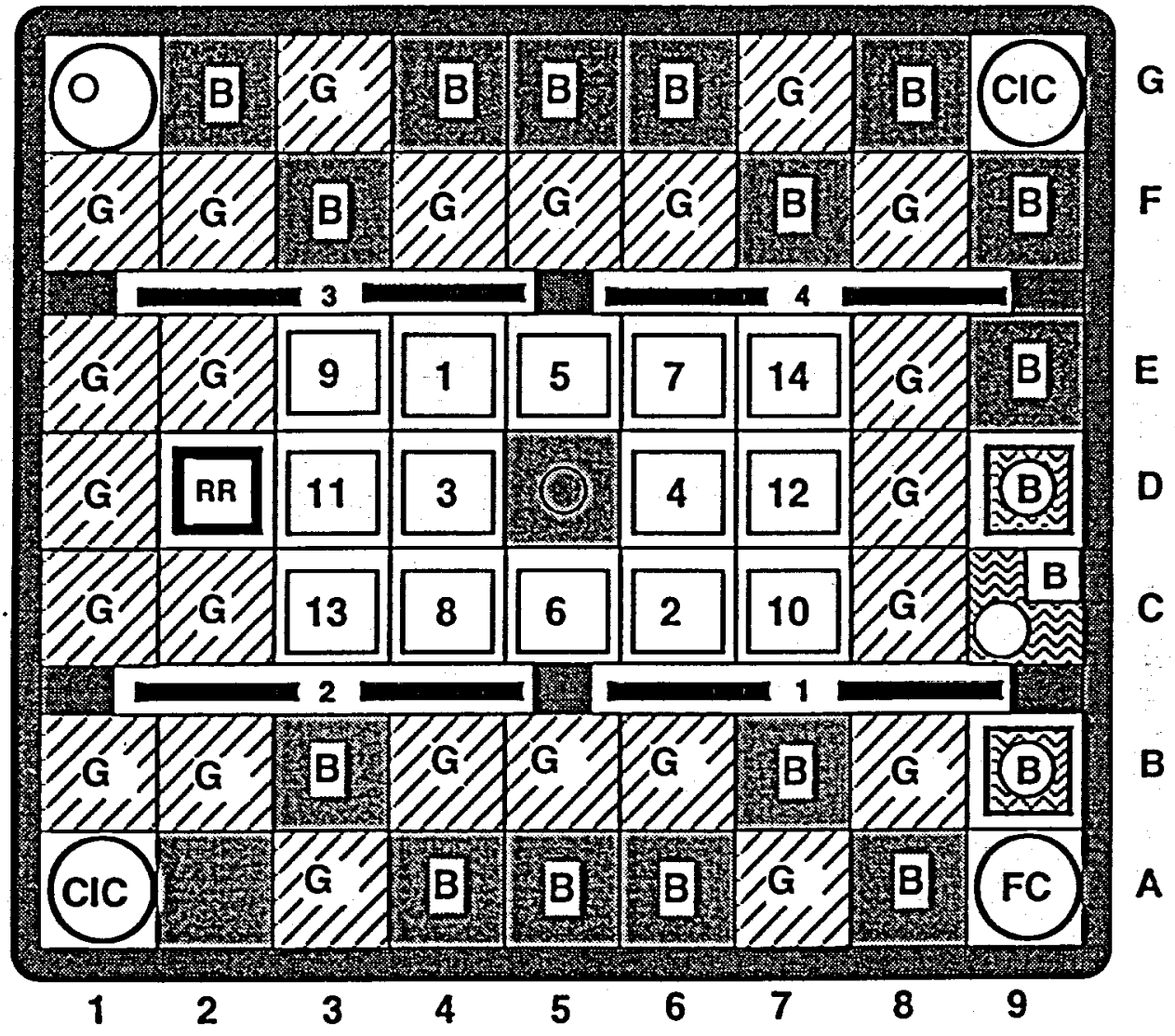

Beryllium Reflector

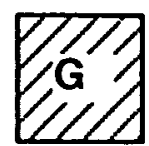

Graphite Reflector

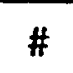

Fuel element

As of 9-30-1995 the isotope weight of fuel was $3641.02 \mathrm{gms}$

FIGURE 4 
LEU -- CORE \#2

\section{May 1994}

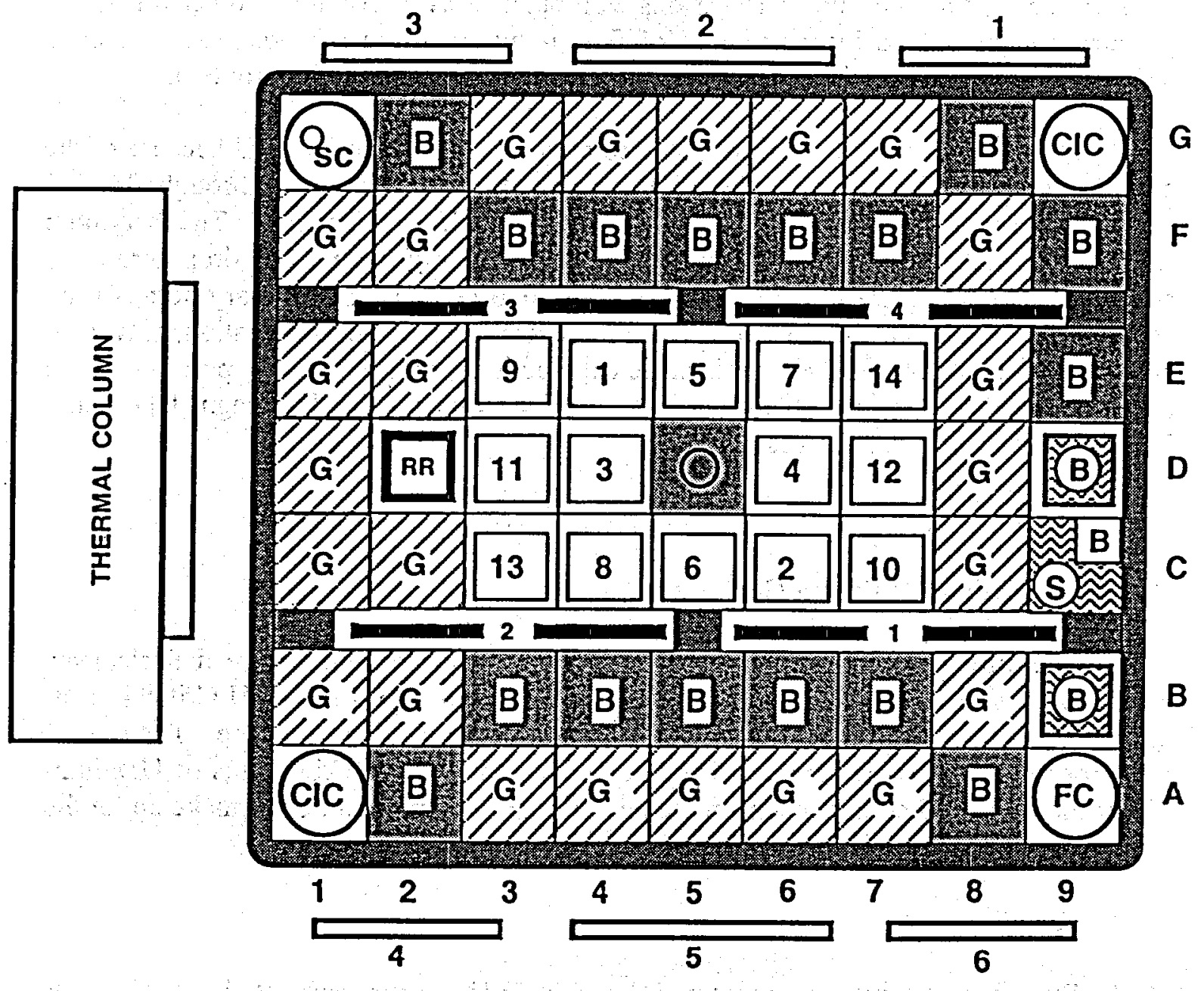

FIGURE 5 
Another problem associated with a low position of the rods in the core was vibration of the rods due to the coolant flow in the shrouds. The vibrations cause reactor power oscillations up to $10 \%$ depending on rod height. This phenomenon had been observed in the initial operation of the HEU core but it diminished as the rods were withdrawn to compensate for fuel burn up. Discussions with other research reactors indicated that this problem can be solved by installation of flow reducers in the shrouds. The corrective action for the detector problem previously mentioned also resolved the problem.

A reduction in primary flow occurred after the conversion to LEU because of the compact core configuration. The HEU core had coolant flowing through 30 fuel elements. The LEU core has coolant flowing through 14 elements. The beryllium reflectors do not have flow channels which results in a higher pressure drop across the core and decreased primary flow by $90 \mathrm{gpm}$ to $1640 \mathrm{gpm}$. Larger primary pumps were installed that increased the flow to acceptable levels for one pump operation, However, two pump operation resulted in insufficient suction pressure at the pumps due to excessive head loss. this problem was resolved by replacing the diaphragm type pump isolation valves with gate valves.

\section{TEST RESULTS}

\section{Initial Criticality: Minimum Core Size}

The critical mass for the LEU start up core occurred with twelve fuel elements which equates to 3300 grams of Uranium-235. Figure 6 shows the LEU Critical mass. The numbers in the boxes for fuel elements describe the loading sequence. The critical mass for the initial HEU core consisted of 21 elements and 2.6 kilograms of Uranium235. Since the LEU core is much smaller, additional fuel was required to make up for the larger neutron leakage experienced by this core.

\section{Excess Reactivity}

Excess reactivity was measured for the LEU startup core at $2.70 \% \Delta K / K$ as compared to a design calculation of $3.0 \Delta k / k$. The Excess reactivity for a 30 element HEU startup core was measured at $4.5 \% \Delta \mathrm{k} / \mathrm{k}$. The design and measured values for both cores compared favorably and are within the Technical Specification limit of $4.7 \% \Delta \mathrm{K} / \mathrm{K}$. 
INITIAL CORE LOADING CRITICAL

12 element CORE \#1

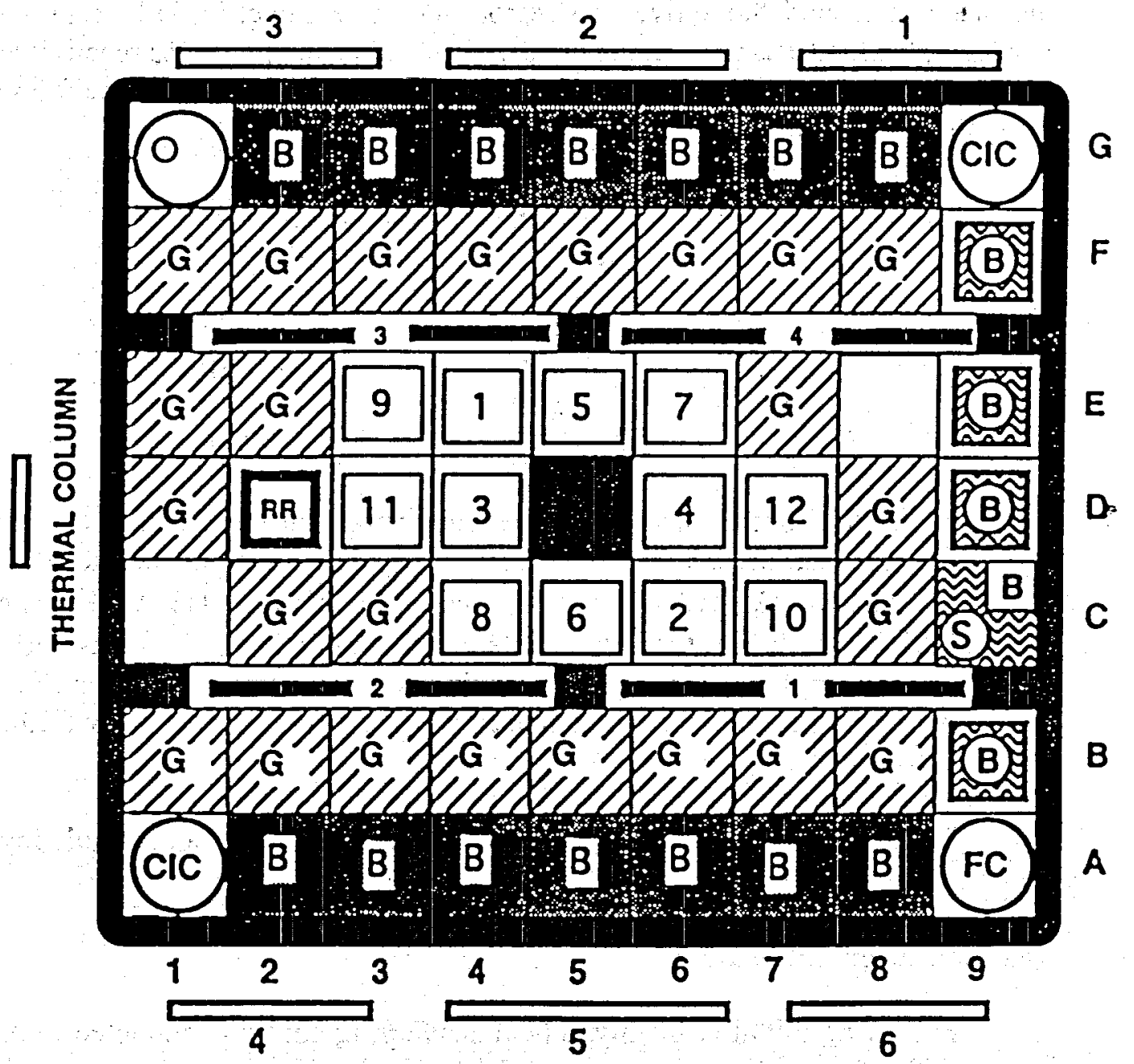

CRITICAL WITH 14 FUEL ELEMENTS

BLADES 1, 2, 3 - 26.6" full out

BLADE $4 \quad-17.16^{\prime \prime}$

Regulating Blade 23.5" - full out

Berylium Flux Trap with plug 


\section{Control and Regulating Rod Calibrations}

In the HEU core, control blades 2 and 3 had a worth of $3.0 \% \Delta \mathrm{K} / \mathrm{K}$ and blades 1 and 4 had a worth of $2.8 \% \Delta \mathrm{K} / \mathrm{K}$. The lower value for blades 1 and 4 was due to their location which placed more of the blade surface in the reflector region. In the LEU core, the blades surround the active fuel region and are symmetric with respect to the flux. However, the blades are not in the highest flux region and have less reactivity effect when compared with the HEU core which had a much flatter flux profile. The following results were obtained for the LEU start up core:

$\begin{array}{ccc}\text { Blade } & \begin{array}{c}\text { reactivity } \\ \text { predicted }\end{array} & \begin{array}{c}(\% \Delta K / K) \\ \text { measured }\end{array} \\ & & \\ 1 & -2.39 & -2.27 \\ 2 & -2.39 & -2.10 \\ 3 & -2.39 & -2.30 \\ 4 & -2.39 & -2.16\end{array}$

While the control blade measurements were consistent with the predictions, the regulating rod measured value was significantly less than the predicted value. The measured value was $.269 \% \Delta \mathrm{K} / \mathrm{K}$ and the predicted value was $.41 \% \Delta \mathrm{K} / \mathrm{K}$. The $H E U$ core had a $.48 \% \Delta K / K$. While the new stainless steel regulating rod has less effect than the previous boral rod, the control system has functioned properly in automatic with the new regulating rod which indicates that it has sufficient reactivity and no further action is planned.

Differential rod worth curves for the control blades and regulating blade are contained in Figures 7 through 11.

\section{Reactor Power Calibration}

Following initial criticality, an extensive program was conducted to map the flux in the reactor core, reflector region and facilities. Foils and wires were irradiated at low power to determine a detailed map of radial and axial flux. The flux profile was integrated to obtain a calculated reactor power of 12.5 watts which compared closely to the indicated power of $\mathbf{1 0}$ watts. The wide range linear channel detectors were adjusted and power was increased to $100 \mathrm{KW}$ and then $500 \mathrm{KW}$ while checking consistency between the 
Blade 1 vs $2,3,4$

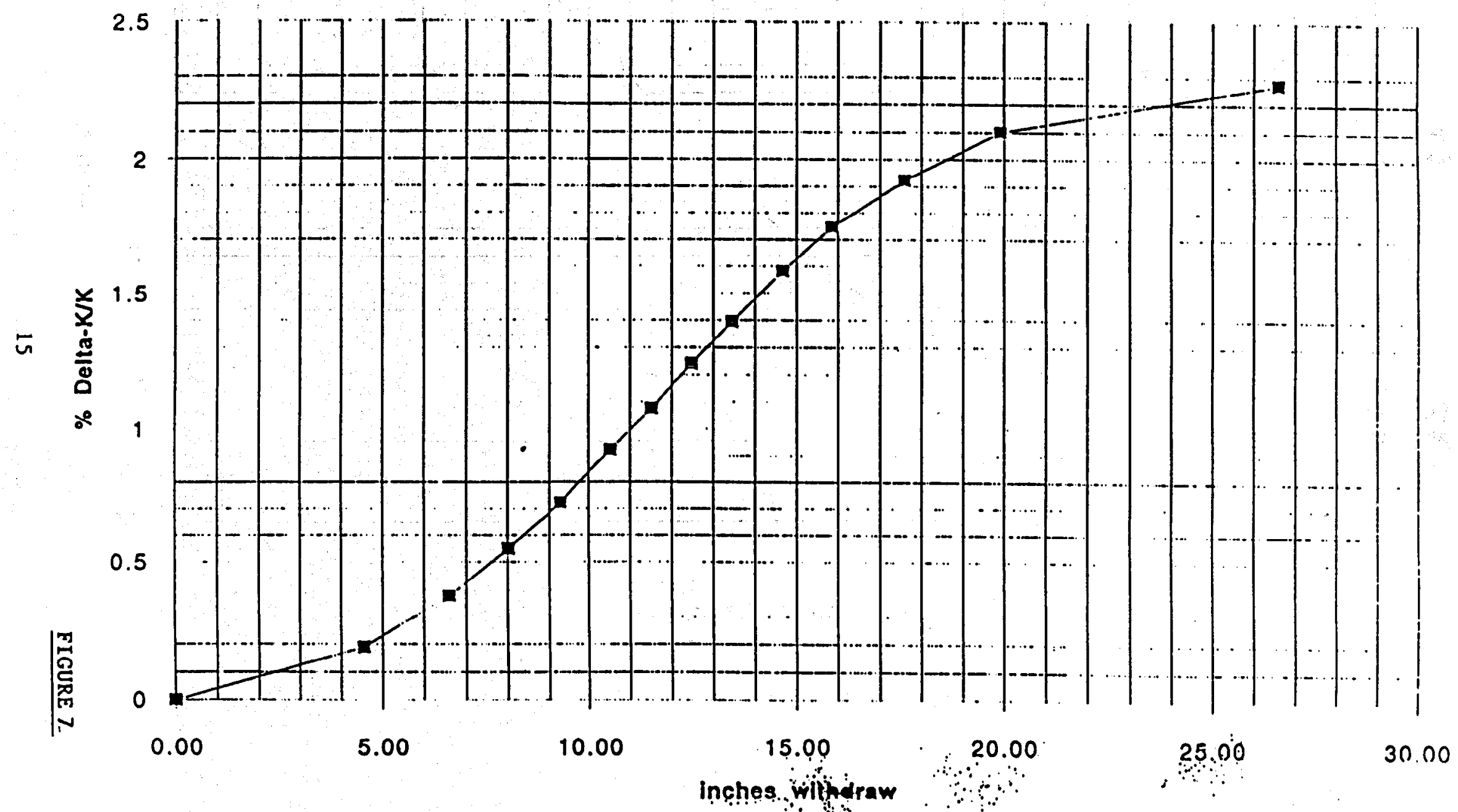


Blade 2 vs $1,3,4$

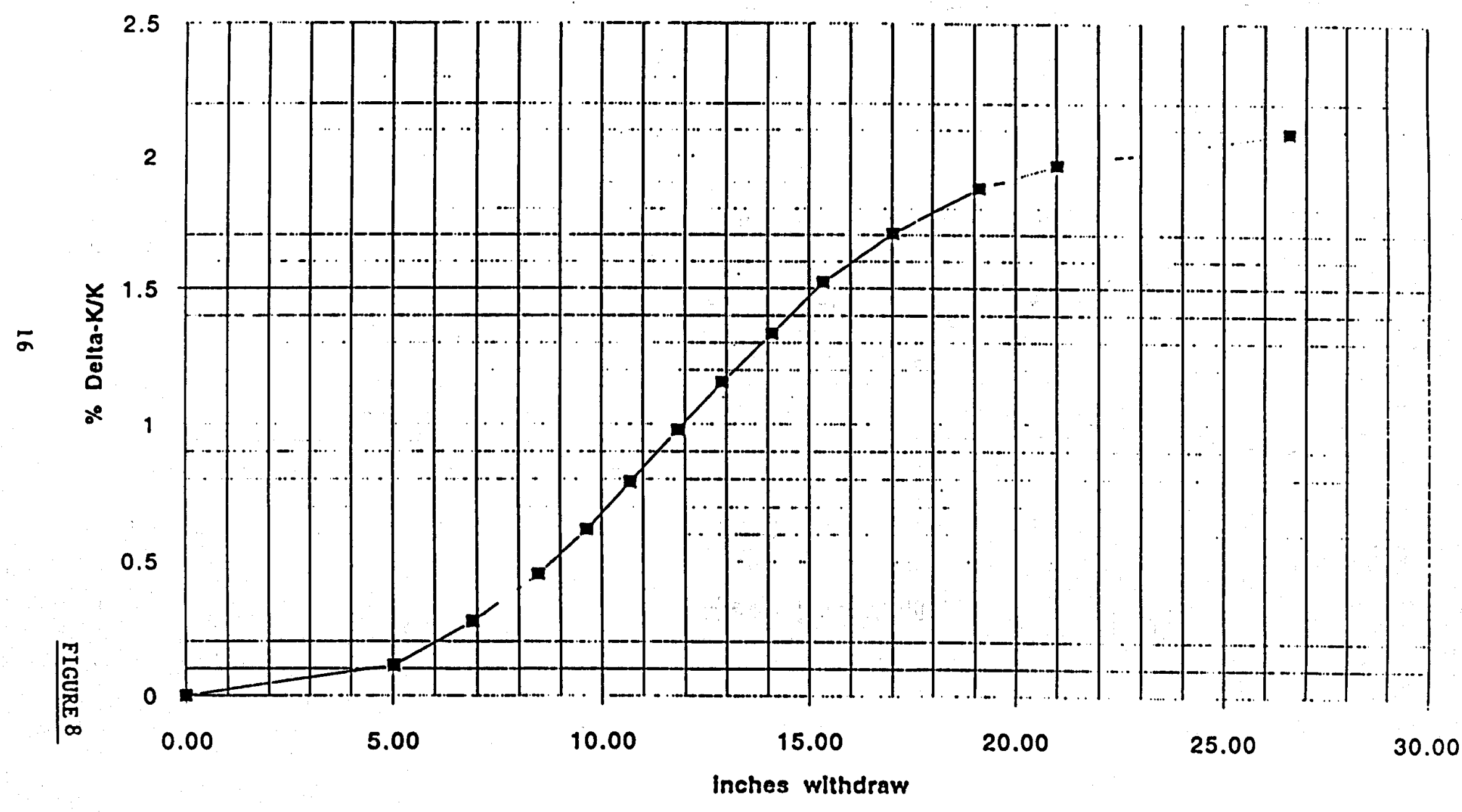




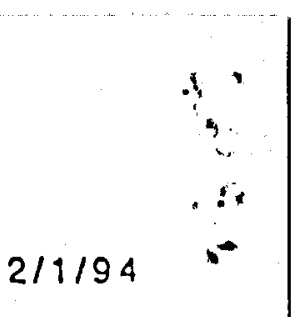

Blade 3 vs $1,2,4$

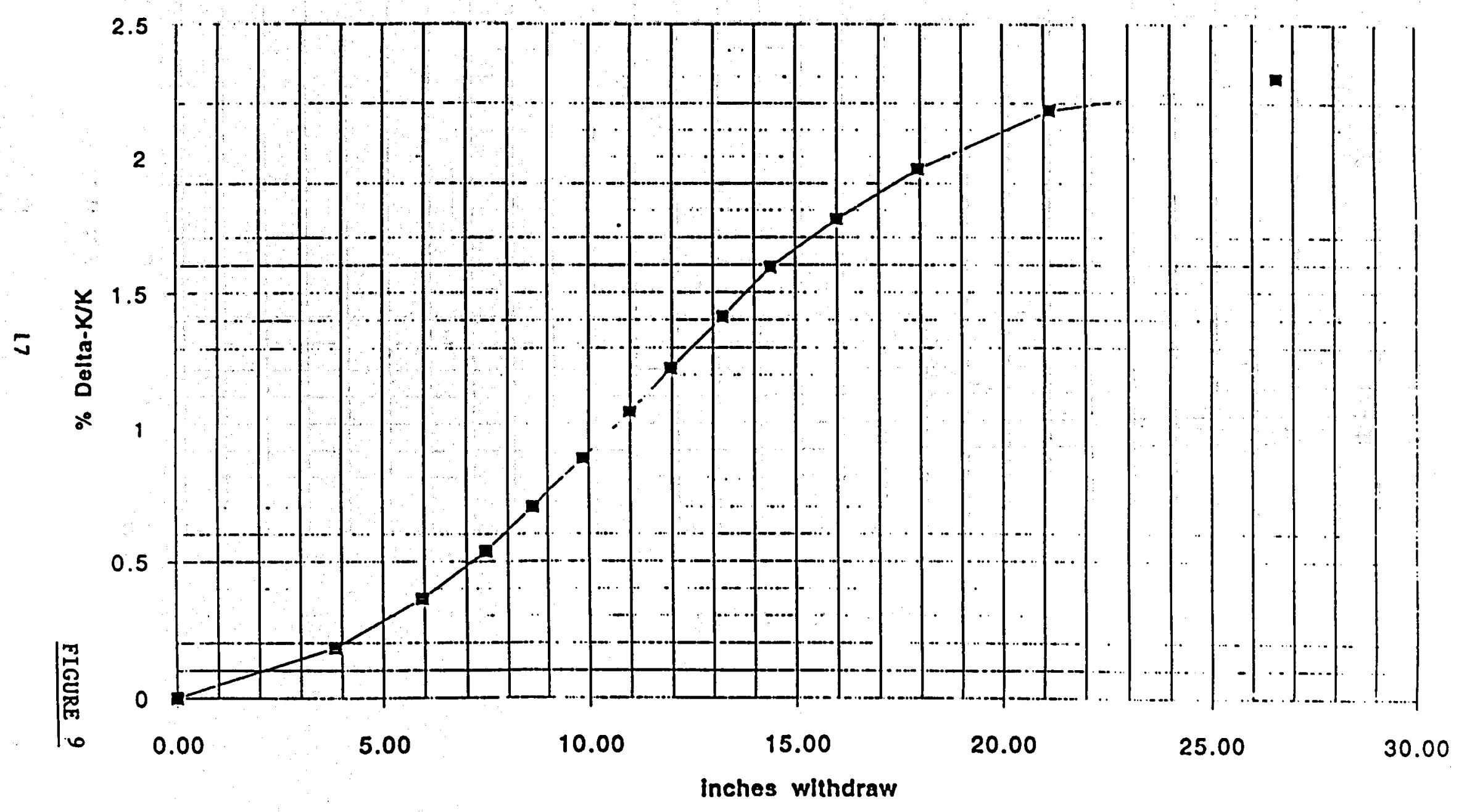


Blade 4 vs $1,2,3$

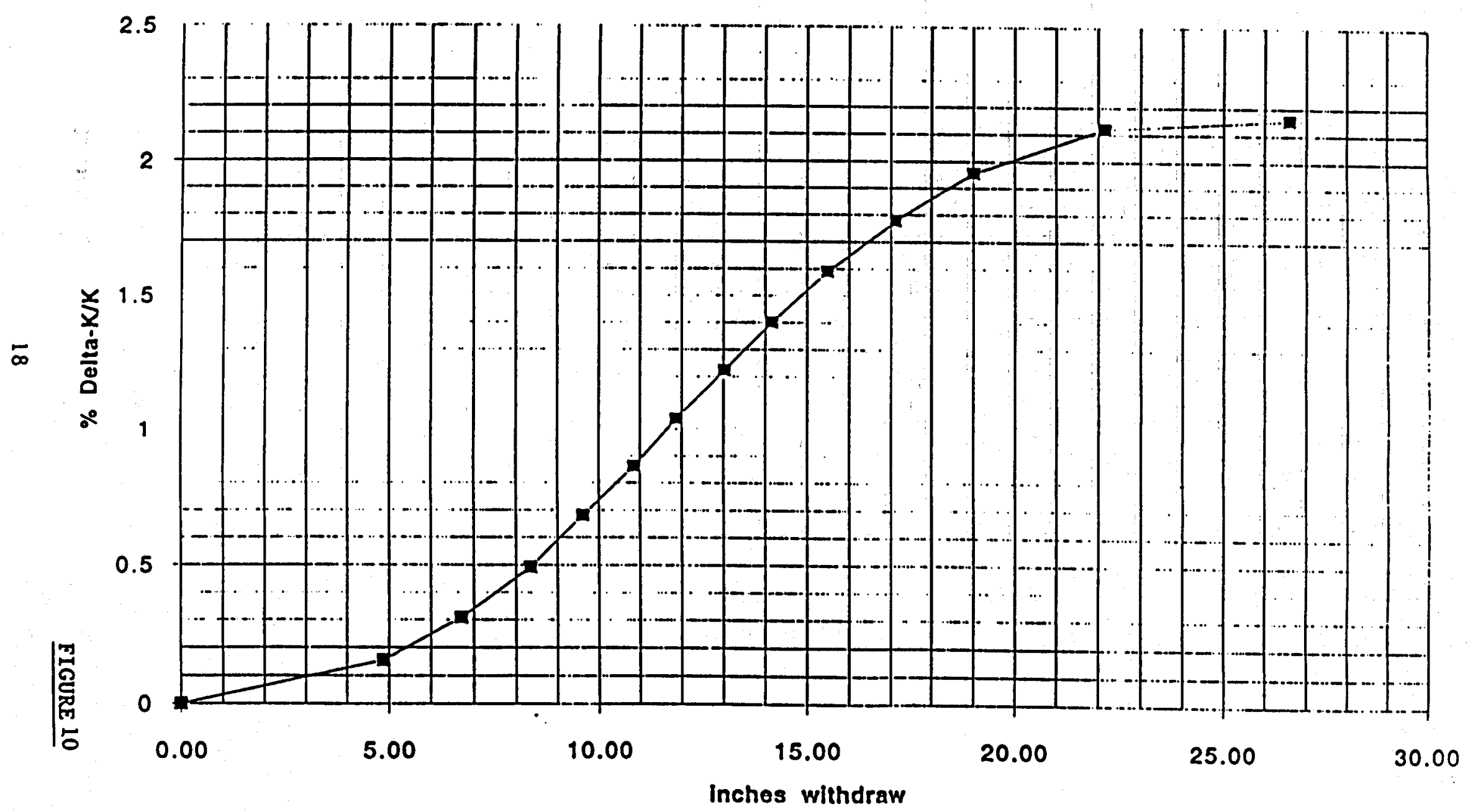




\section{Regulating Blade}

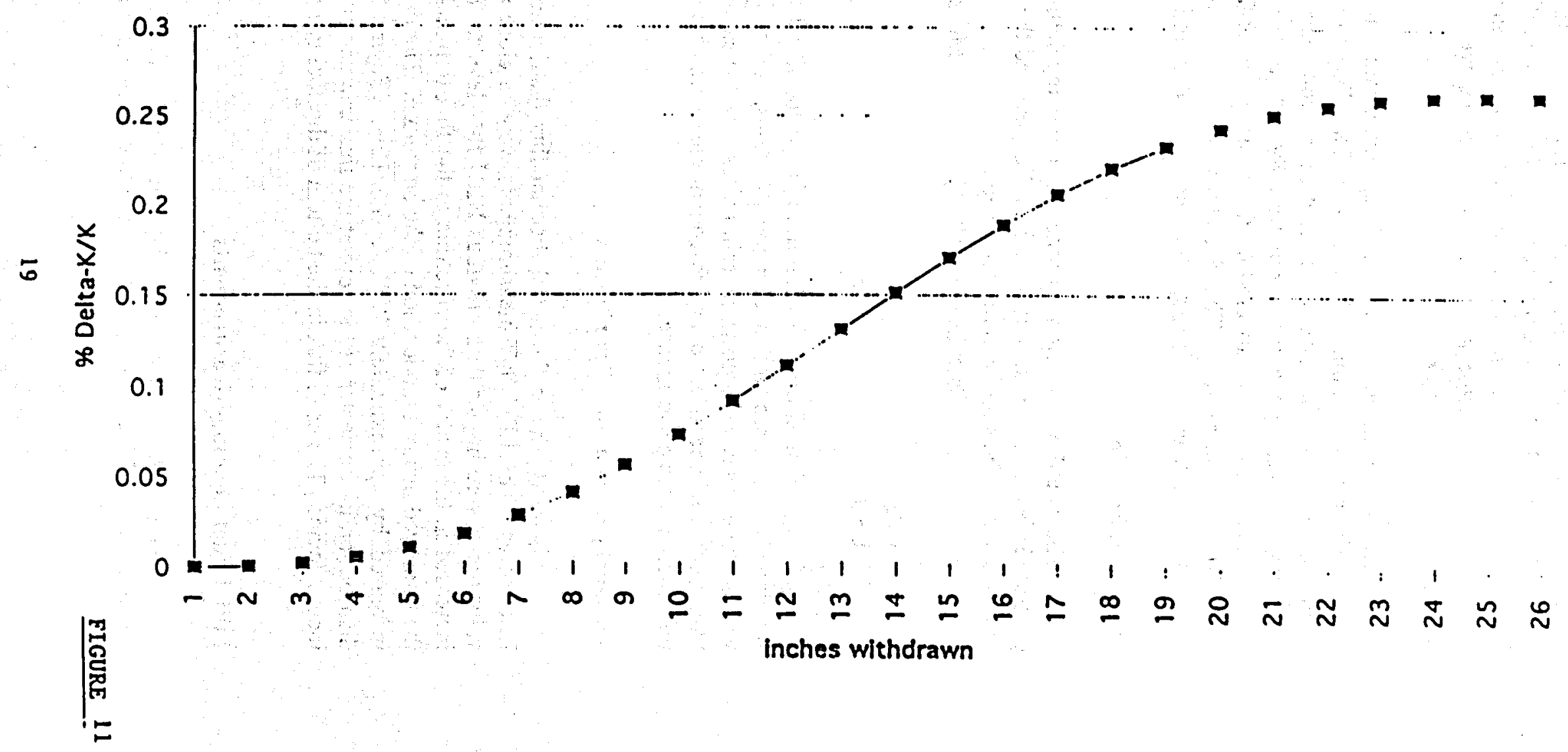


wide range linear channels and the nitrogen-16 monitor and the delta $T$ of the primary hot and cold legs. After verifying consistency between these instruments, reactor power was increased to $1 \mathrm{MW}$ to conduct a calorimetric calibration. The resulting instrument adjustments were less than $3 \%$. Calorimetric calibrations were then conducted at $75 \%$ and $90 \%$ and $95 \%$ reactor power and measurements were within $3 \%$ of actual power and nitrogen-16 readings.

As part of the conversion, the High flux scram setting was reduced to $115 \%$ from $130 \%$. The alarm set point remained at $110 \%$. Due to the problem with the detectors being located above the core, the current of the compensated ion chambers that provide wide range power signals was initially only $25 \%$ of the HEU value at a given power level. The detectors were lowered in the corner posts as far as possible to place them in the maximum neutron flux. This detector position has proven satisfactory for providing adequate adequate current for adjusting the instrument settings.

\section{Shutdown Margin}

The shutdown margin assumes that the regulating rod and the most reactive control blade are fully out. For both the HEU core and the LEU core, blade three was the most reactive. The shutdown margins were:

$$
\text { Calculated }(\% \Delta \mathrm{K} / \mathrm{K}) \quad \text { Measured }(\% \Delta \mathrm{K} / \mathrm{K})
$$

HEU

LEU

The Technical Specification limit is greater than $1.0 \% \Delta \mathrm{K} / \mathrm{K}$. The HEU and LEU shutdown margins are well within specifications. Like all the observed LEU reactivity values, the observed shutdown margin is less than the calculated value. These parameters have remained consistent over subsequent measurements and believed to be an accurate reflection of core performance.

\section{Thermal Neutron Flux Distributions}

Figure 10 shows the radial thermal flux distribution at $2 \mathrm{MW}$ for the HEU and LEU cores. The LEU flux measurements were in close agreement with the calculated values and were higher than previous HEU flux levels. Thermal flux was significantly increased in the center of the core due to the flux trap and in the reflector region due to the improved neutron moderation of the beryllium. The thermal flux in the rabbit system increased by approximately $25 \%$ to $3.6 \times 10^{12}$. Figure 5 and 6 show the axial flux distribution in the center of the core at the flux trap and at the periphery of the core in an incore device. The peak flux in the bottom of the core is evident in both locations.

\section{Initial Fuel Loading Measurements}

As previously discussed, the initial criticality experiment was conducted by performing a $1 / \mathrm{M}$ calculation after each fuel element addition. Figure 12 shows the 
loading sequence and Figure 13 displays the $1 / \mathrm{M}$ graph for the test. Criticality was achieved with 12 elements installed and three of the blades fully withdrawn and the fourth blade at seventeen inches. The slow, deliberate approach taken ensured that criticality was achieved in a controlled manner. The initial placement of the test source in the center of the core resulted in a stable source level throughout the test. When it was moved for the last element addition, count rate was sufficiently high and stable to properly monitor the increase in reactivity from addition of the final element. 
Thermal Neutron Flux Dist HEU vs LEU at 2MW

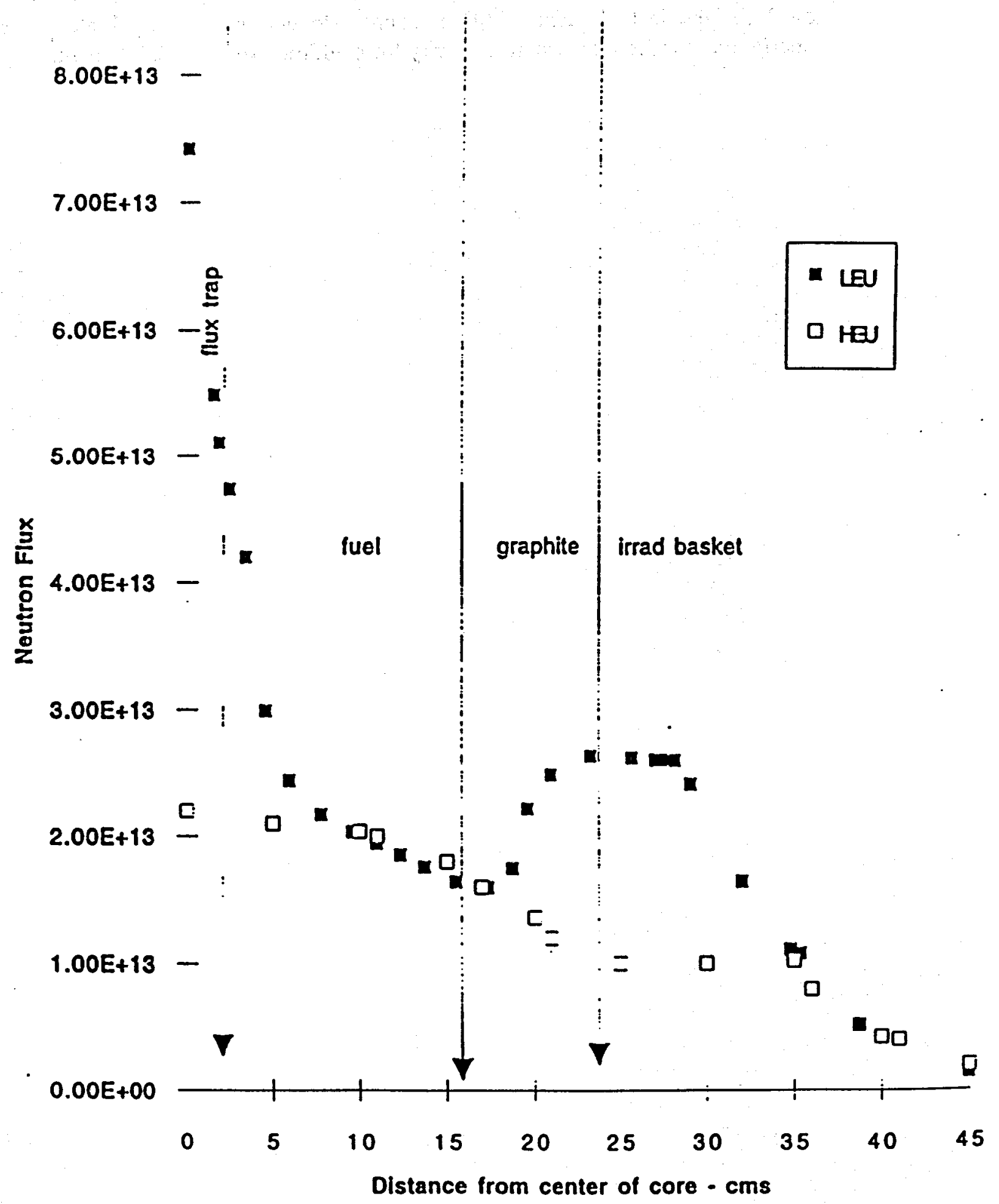

FIGURE 12 
LEU CRITICAL EXPERUMENT II 8/18/88

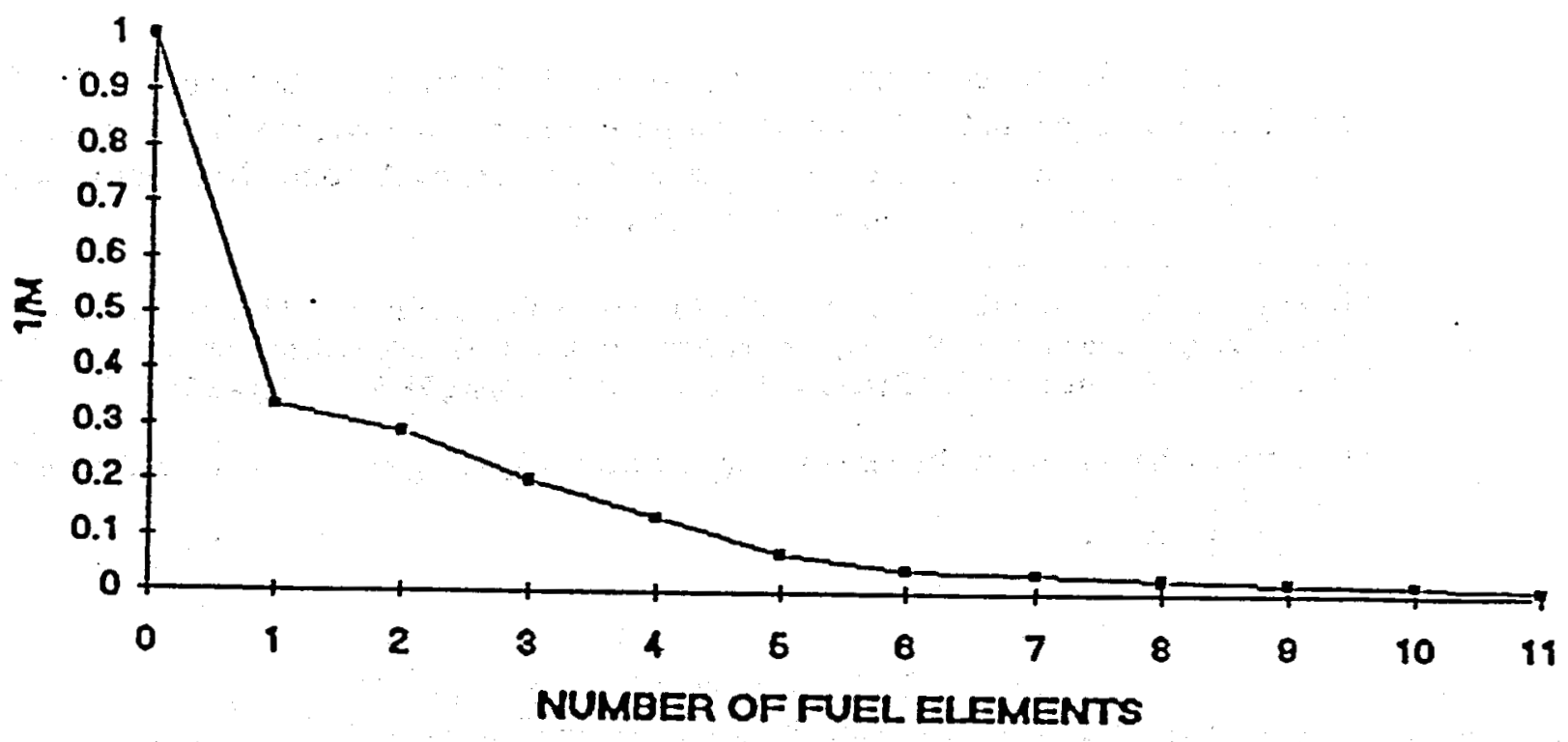




\section{Negative Temperature Coefficient}

The Technical Specification requirement for Negative Temperature Coefficient requires that it be checked after change in fuel type and that the value be negative. The calculated value for the HEU reference core was $-2.0 \Delta \mathrm{K} / \mathrm{K} \times 10^{-4} /{ }^{\circ} \mathrm{C}$ and the calculated value for the start up $\mathrm{LEU}$ core was $-1.8 \% \Delta \mathrm{K} / \mathrm{K} \times 10^{-4} /{ }^{\circ} \mathrm{C}$. The actual value was determined to be negative by core reactivity and temperature measurements conducted on October 7, 1994.

\section{Void Coefficient of Reactivity}

The void coefficient for the HEU core was calculated at $-1.5 \times 10^{-3} \% \Delta \mathrm{K} / \mathrm{K} / \%$ void. The calculated value for the LEU core was $-2.7 \times 10-3 \% \Delta \mathrm{K} / \mathrm{K} / \%$ void. The measured void coefficient for the LEU core was $-3.3 \times 10^{-3} \% \Delta \mathrm{K} / \mathrm{K} / \%$ void which compared favorably with the calculated value.

\section{SUMMARY}

Results for the conversion of the core to LEU are quite favorable. The design objectives have been met and a significant performance improvement has been achieved. Operating data on the LEU core and subsequent analyses by Argonne National Laboratory indicate that a power upgrade to $5 \mathrm{MW}$ is feasible.

\footnotetext{
' DiMeglio, A.F., Matos, J.E., and Freese, K.E.: Conversion, Core Redesign and Upgrade of Rhode Island Atomic Energy Commission Reactor, Proceedings of the 1987 International Meeting on Reduced Enrichment for Research and Test Reactors, Buenos Aires, Argentina, 28 September - 10 October, 1987.

${ }^{2}$ Glasstone, Samuel \& Alexander Sesonske, Nuclear Reactor Engineering, Van Nostrand Company, New York, 1981, p.247.
} 